\title{
Le Moyen Âge vu d'ailleurs II. Historiographie et recherches actuelles
}

São Paulo, 27-31 octobre 2003

\section{Eliana Magnani}

\section{(Q) OpenEdition}

\section{Journals}

Édition électronique

URL : https://journals.openedition.org/cem/3402

DOI : $10.4000 /$ cem.3402

ISSN : 1954-3093

Éditeur

Centre d'études médiévales Saint-Germain d'Auxerre

Édition imprimée

Date de publication : 15 août 2003

ISSN : 1623-5770

\section{Référence électronique}

Eliana Magnani, «Le Moyen Âge vu d'ailleurs II. Historiographie et recherches actuelles », Bulletin du centre d'études médiévales d'Auxerre | BUCEMA [En ligne], 7| 2003, mis en ligne le 05 décembre 2007, consulté le 22 septembre 2022. URL : http://journals.openedition.org/cem/3402 ; DOI : https://doi.org/ 10.4000/cem.3402

Ce document a été généré automatiquement le 22 septembre 2022.

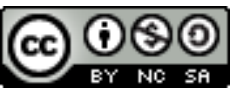

Creative Commons - Attribution - Pas d'Utilisation Commerciale - Partage dans les Mêmes Conditions 4.0 International - CC BY-NC-SA 4.0

https://creativecommons.org/licenses/by-nc-sa/4.0/ 


\section{Le Moyen Âge vu d'ailleurs II. Historiographie et recherches actuelles}

São Paulo, 27-31 octobre 2003

\section{Eliana Magnani}

1 Un an après la rencontre d'Auxerre, le deuxième atelier de formation à la recherche et d'étude réunissant des médiévistes français et sud-américains (argentins et brésiliens) se tiendra à l'Université de São Paulo, au Brésil, fin octobre $2003{ }^{1}$. Dans le souci d'associer des médiévistes d'autres horizons, nous avons convié des collègues espagnols et portugais à participer à cette deuxième rencontre au cours de laquelle, avec leur aide, nous poursuivrons les discussions sur les traditions historiographiques et les tendances actuelles de la médiévistique, en particulier en Espagne, au Portugal et en France. Réalisé en présence d'un public d'étudiants important et rassemblant des médiévistes qui n'ont pas vraiment l'occasion de se rencontrer, l'un des objectifs de l'atelier de São Paulo est d'assurer la diffusion de travaux de recherche récents et stimuler les échanges. Ainsi, au cours de ces journées, les différents participants présenteront et discuteront leurs travaux dont certains reprendront des questions soulevées dans l'atelier auxerrois, comme l'utilisation des sources iconographiques, la notion de communauté ou l'individu.

Lundi 27 octobre

- Ouverture (H. Franco Jr.).

- Présentation du programme et tour de table (E. Magnani).

Historiographie I

2 Coordination : Maria Inés Carzolio

- Tradiciones y tendencias en el medievalismo español (P. Martinez Sopena).

- História da Idade Média em Portugal : tendências e pesquisas (J. A. Gonçalves de Freitas). Historiographie II 


\section{Coordination : Marcelo Cândido da Silva et Pablo Ubierna}

- La médiévistique en France : autour du livre Tendances actuelles de l'Histoire du Moyen Âge en France et en Allemagne, dir. J.- Cl. Schmitt, O. G. Oexle, Paris, Publ. de la Sorbonne, 2002.

- Présentation de l'ouvrage (J.-Cl. Schmitt).

- Bilan historiographique et nouveaux chantiers de recherche en France (M. Bourin, D. IognaPrat, J. Morsel, J.-Cl. Schmitt).

Mardi 28 octobre Recherches actuelles I

Coordination : Mário Jorge da Motta Bastos

- Literatura profética y poder en Byzancio durante los siglos VIII al X (P. Ubierna).

- Discurso, gestos y comunicación en la liturgia visigoda (589-711) (E. Dell'Elicine).

Recherches actuelles II

5 Coordination : Hilário Franco Jr.

- Histoire de l'art et iconographie (D. Russo).

- Os pilares do claustro de Moissac (M. C. Pereira).

- Problèmes de l'image médiévale pour l'historien médiéviste (J.-Cl. Schmitt).

Mercredi 29 octobre Recherches actuelles III

Coordination : Flávio de Campos

- La notion de fait dans l'espace judiciaire (M. Madero).

- Entre memoria y olvido. El tiempo de la costumbre en el derecho medieval (P. Miceli).

Recherches actuelles IV

\section{Coordination : Pascual Martinez Sopena}

- Dom e intercâmbios na alta Idade Média (E. Magnani).

- La crise des années 1300 (M. Bourin).

- Les logiques communautaires entre logiques spatiales et logiques catégorielles (XII $-\mathrm{XV}^{\mathrm{e}} \mathrm{s}$.)

(J. Morsel).

Jeudi 30 octobre Recherches actuelles V

\section{Coordination : Néri de Barros Almeida}

- Individu et identité au Moyen Âge (D. Iogna-Prat).

- Individu et péché au Moyen Âge (A. Morín).

Recherches actuelles VI

\section{Coordination : Marta Madero}

- A agonia lúdica : guerra, competição e fortuna nos jogos medievais (F. de Campos).

- Os sinais da infâmia e o vestuário mouro em Portugal nos séculos XIV e XV (J. Rivair

Macedo).

- Considerações finais (L. M. Mongelli).

Vendredi 31 octobre

Visite de la ville, du "Museu de Arte Sacra de São Paulo" et de la "Fundação Maria Luíza e Oscar Americano".

\section{Participants :}


- Néri DE BARRos ALMEIDA (Univ. Estadual Paulista - Franca)

- Monique Bourin (Univ. de Paris I)

• Flávio DE CAMPOS (Univ. de São Paulo)

- Marcelo CÂNDIDo Da Silva (Univ. de São Paulo)

- María Inés CARzolio (Univ. Nacional de Rosario)

- Vivian COUTINHO DE ALMEIDA (Univ. de São Paulo)

- Eleonora Dell'Elicine (Univ. de Buenos Aires, Univ. Nacional de General Sarmiento)

- Hilário FRANCO Jr. (Univ. de São Paulo)

- João gomes (Univ. Estadual Paulista - Franca)

-Judite A. GONÇALVES De Freitas (Univ. Fernando Pessoa - Porto)

- Dominique IOGNA-PRAT (CNRS UMR 5594 Auxerre/Dijon)

- José RIVAIR MACEDo (Univ. Federal do Rio Grande do Sul)

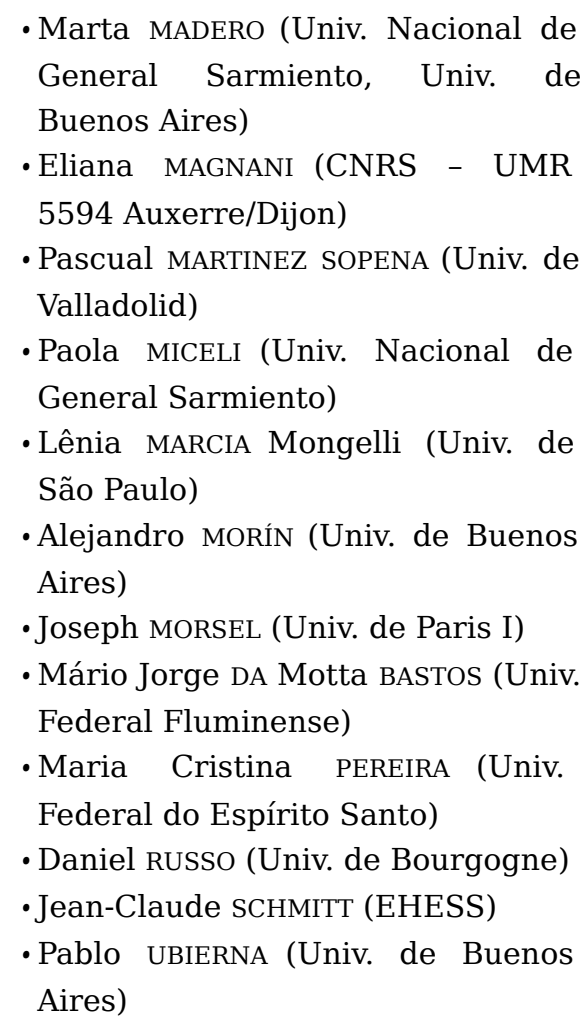
General Sarmiento, Univ. de Buenos Aires)

- Eliana MAGNANI (CNRS - UMR 5594 Auxerre/Dijon)

- Pascual MARTINEZ SOPENA (Univ. de Valladolid)

- Paola MICELI (Univ. Nacional de General Sarmiento)

- Lênia MARCIA Mongelli (Univ. de São Paulo)

- Alejandro MORÍN (Univ. de Buenos Aires)

- Joseph MORSEL (Univ. de Paris I)

- Mário Jorge DA Motta BASTOS (Univ. Federal Fluminense)

- Maria Cristina PEREIRA (Univ. Federal do Espírito Santo)

- Daniel Russo (Univ. de Bourgogne)

- Jean-Claude SCHMitT (EHESS)

- Pablo UBIERna (Univ. de Buenos Aires)

\section{NOTES}

1.Sur les principes généraux du programme d'ateliers "Le Moyen Âge vu d'ailleurs", voir Bulletin du Centre d'études médiévales d'Auxerre, Études et travaux, 6 (2001-2002), p. 156-159. Sur la première rencontre à Auxerre, voir le compte rendu et les contributions dans ce volume p. 93-131. 